J Chron Dis 1974, Vol. 27, pp. 507-516. Pergamon Press. Printed in Great Britain

\title{
BIOLOGIC VARIATION OF HUMAN SERUM IMMUNOGLOBULIN CONCENTRATIONS: SEX-AGE SPECIFIC EFFECTS*
}

\author{
James T. Cassidy, Gordon L. Nordby and HoraCe J. Dodge
}

Rackham Arthritis Research Unit, Departments of Internal Medicine and Biological Chemistry, Medical School, and the Department of Epidemiology, School of Public Health, The University of Michigan, Ann Arbor, Michigan, U.S.A.

(Received 11 December 1973)

\section{INTRODUCTION}

SER UM immunoglobulin determinations are of potential value to clinicians in evaluating immunoinflammatory diseases and in the detection and characterization of immunodeficiency or hypergammaglobulinemia. Certain biologic variables affect concentrations of serum immunoglobulins [1-4] and must be considered in interpretation of specific levels in any individual patient. Efforts by different authors to determine general norms of immunoglobulin concentrations and life-time trends have diverged considerably. The present study of sex and age effects on serum concentrations of $\mathrm{IgG}, \mathrm{IgA}$, and IgM is based on data from a large unselected group of subjects from a single community.

\section{MATERIALS AND METHODS}

\section{Study group}

3213 consecutive sera were obtained in a community health study in Tecumseh, Michigan ( $42^{\circ} \mathrm{N}$ latitude, $83^{\circ} \mathrm{W}$ longitude) from May 1968 to April 1969. All individuals were of the white race. Sera were divided aseptically into aliquots and stored at $4^{\circ} \mathrm{C}$; they were either assayed within a week or frozen at $-70^{\circ} \mathrm{C}$ until analysis.

\section{Preparation of purified immunoglobulins and antisera}

IgG was prepared from Cohn Fraction II (American Red Cross, Bethesda, Md.) by DEAE-cellulose (Carl Schleicher \& Schuell Co., Keen, N.H.) chromatography with $0.0175 \mathrm{M}$ phosphate buffer, $\mathrm{pH} 6.3$ [5]. IgA was prepared from myeloma sera by

\footnotetext{
*This work was supported by grants from the Institute of Gerontology of The University of Michigan and Wayne State University, The University of Michigan Medical School Fund for Computing, and the Michigan Chapter of The Arthritis Foundation. The Rackham Arthritis Research Unit is supported in part by a grant from the Horace H. Rackham School of Graduate Studies. The Tecumseh Communith Health Study is supported by Program Project Grant HL 09814 from The National Heart and Lung Institute, National Institutes of Health.
}

Reprint requests should be addressed to Dr. Cassidy, R4633 Kresge Medical Research Bldg, The University of Michigan Medical School, Ann Arbor, Michigan 48104. 
starch block electrophoresis in $0.075 \mathrm{M}$ barbital buffer, $\mathrm{pH} 8.6$ [6], and Sephadex G-200 (Pharmacia, Uppsala, Sweden) filtration with $1 \mathrm{M} \mathrm{NcCl}$ in $0.1 \mathrm{M}$ Tris- $\mathrm{HCl}$ buffer, $\mathrm{pH} 8.2$ [7]. IgM was isolated from macroglobulinemic sera by plasmapheresis, euglobulin precipitation [8], and Sephadex G-200 filtration. Light chains were isolated from urines of patients with myeloma by precipitation with $60 \%$ ammonium sulfate at $4^{\circ} \mathrm{C}$ followed by gel permeation chromatography on Sephadex G-100. The specificity of the isolated immunoglobulins and light chains was monitored by double diffusion in gel [9] and by immunoelectrophoresis [10] against antisera to each of the immunoglobulins and to whole serum. Antisera prepared in rabbits with specific immunoglobulins emulsified in Freund's complete adjuvant (Difco Laboratories, Detroit, Mich.) were cross-adsorbed with purified immunoglobulins and light chains.

\section{Preparation of standard sera}

The purified immunoglobulins were assayed for protein nitrogen by a microKjeldahl procedure [11], and approximate Svedberg constants were determined by analytical ultracentrifugation in $0.02 \mathrm{M}$ phosphate, $0.12 \mathrm{M} \mathrm{NaCl}, \mathrm{pH} 7.2$, to be $7 \mathrm{~S}^{\circ}{ }_{20, w}$ for IgG and IgA and $19 \mathrm{~S}^{\circ}{ }_{20, w}$ for IgM [12]. A set of working standards consisted of four dilutions of serum from a healthy donor stored in aliquots at $-70^{\circ} \mathrm{C}$. Immunoglobulin concentrations in these standards were determined by comparison to the purified immunoglobulin standards and to International Reference Preparation $67 / 95$ [13]. International units $/ \mathrm{mg}$ of protein were computed for IgG as 10.4 , IgA 56.4 , and IgM 12.2. Antisera used in this study were compared to two commercially available preparations and produced comparable linear assays.

\section{Quantitation of immunoglobulins in test sera}

Immunoassay was performed by a modification of the radial diffusion method [14], in 0.8 per cent Ionagar No. 2 (Consolidated Lab., Chicago Heights, Ill.) in Tris- $\mathrm{HCl}$ buffer, $\mathrm{L}=0.1, \mathrm{pH} 7.2$. After incubation of the plates at $4^{\circ} \mathrm{C}$ for $18-22 \mathrm{hr}$, a period of time determined experimentally to be within the linear relationship between area of precipitation and concentration of antigen, the perpendicular diameters of the precipitin rings were measured on a micrometer stage of a microscope and averaged. Four dilutions of the standard serum were included on each test plate. The concentration of immunoglobulin was read from a line plotted from the standards which was valid for the following ranges: IgG $3-16 \mathrm{mg} / \mathrm{ml}$, IgA $0.5-2.5 \mathrm{mg} / \mathrm{ml}$, and IgM $0.3-2.0 \mathrm{mg} / \mathrm{ml}$. High and low immunoglobulin concentrations were verified by repeated examination. Sera with low immunoglobulin content were reassayed by the electroimmunodiffusion method of Laurell [15] which has a lower limit of sensitivity of $0.01 \mathrm{mg} / \mathrm{ml}$. Sera with immunoglobulin concentrations in excess of the highest standard values were diluted so that concentration could be evaluated on the linear portion of the scale.

\section{Reproducibility of radial immunodiffusion}

The coefficient of variation for repeated measurements of a standard serum during a 2 -yr period was computed with the formula $100 t_{n_{-1}}$ (S.D./mean) in order to obtain the 95 per cent confidence limits for each assay. These values were \pm 17 per cent for IgG, \pm 20 per cent for IgA, and \pm 27 per cent for IgM. Values for interplate variation during a single day's experiments were \pm 10 per cent for $\mathrm{IgG}, \pm 13$ per cent for IgA, and \pm 16 per cent for IgM. 


\section{Statistical methods}

Nithough immunoglobulin concentration data in $\mathrm{mg} / \mathrm{ml}$ are skewed, a $\log _{\mathrm{e}}$ transformation yielded a dependent variable indistinguishable from a normal distribution. All statistical analyses were performed on transformed data which represented the central \pm 1.96 S.D. of the original samples. This procedure was used to minimize the problem of outliers [16]. Appropriate parametric statistical procedures related to multiple linear regression, tests for significance of regression parameters, and confidence intervals were selected from Hald [17]. Computations were made on the University of Michigan IBM 360/67 duplex computer [18].

The $\log _{e}$ concentration data for each of the six immunoglobulin sex groups were fitted to the model $y=A+B x+C x^{2}+D x^{3}+E x^{4}$, where $x$ is age of the subject in years. The power series was truncated when additional terms produced no improvement in the residual variance of fit about the regression line. Regression curves were computed from the appropriate parameters and 95 per cent confidence limits for the data were computed from the residual variance of fit. Determination of significant age and sex effects was based upon standard tests of the regression parameters at a 5 per cent level of significance. Sex-age specific concentration means and ranges at the 90 per cent level were reinterpreted on a linear scalc for convenience in use.

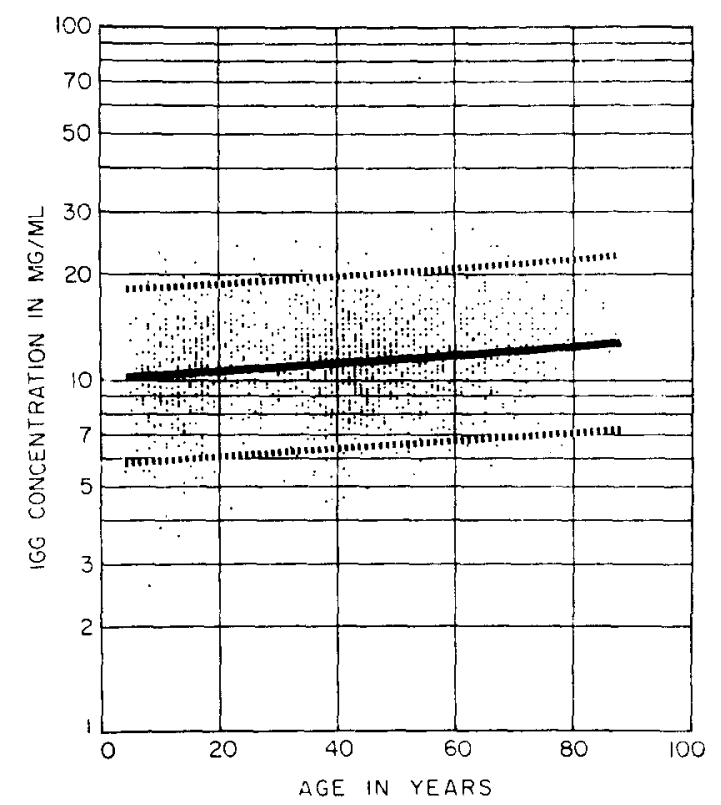

Fig. 1. Regression of $\log _{e} \operatorname{IgG}$ concentrations in males on age for 1489 observations. Number of original observations 1526. Mean age $38,6 \mathrm{yr}$. $\log _{\mathrm{e}}$ concentration mean $=$ 11.17, S.D. $=1.34$

\section{Sex differences}

\section{RESULTS}

Slight but statistically significant sex differences were observed in the age-specific mean serum concentrations of IgG and IgA. These changes are shown in Figs. 1-4. Males were lower than females for IgG, and higher than females for IgA. There was a 


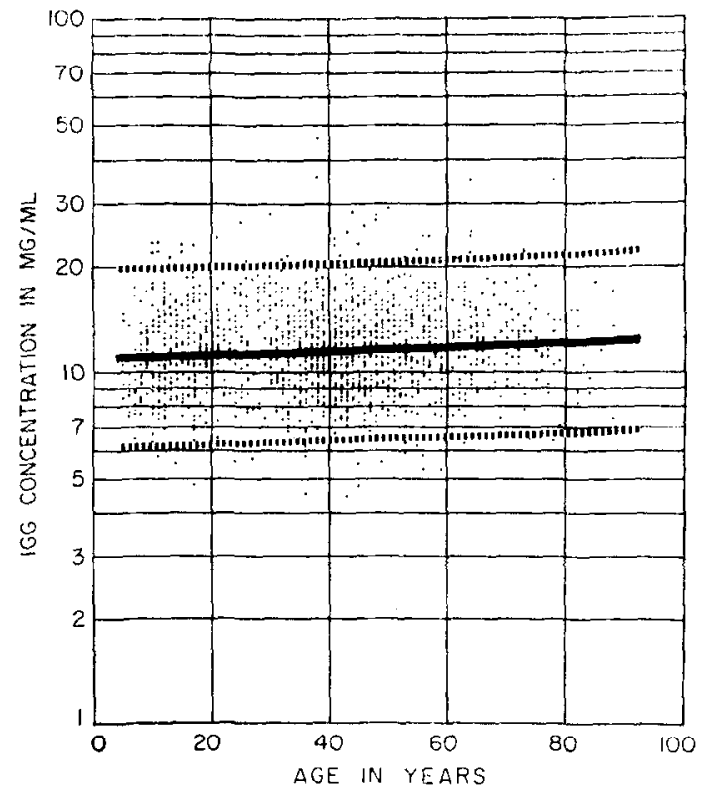

FIG. 2. Regression of $\log _{e}$ IgG concentration in females on age for 1654 observations. Number of original observations 1687. Mean age 38.7 yr. $\log _{e}$ concentration mean $=11.53$, S.D. $=1.35$.

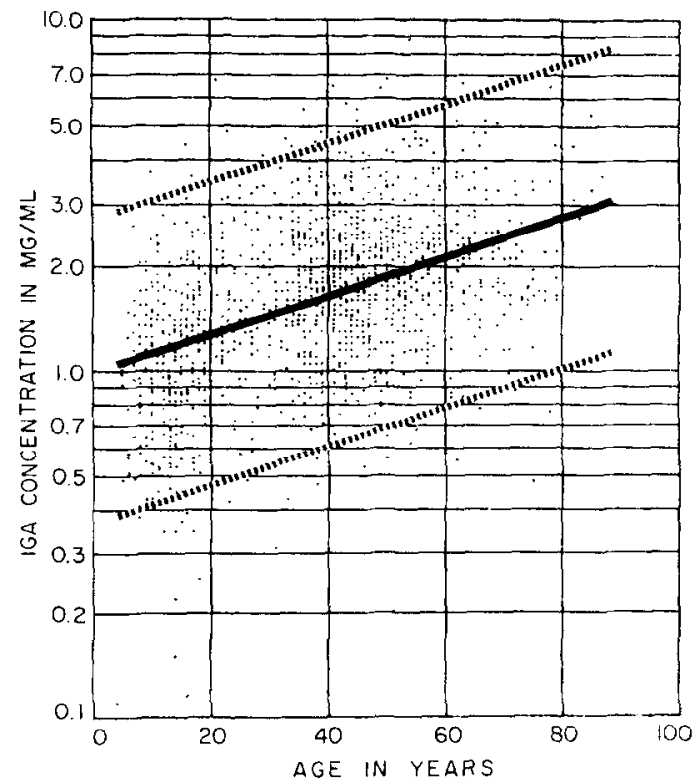

Fig. 3. Regression of $\log _{e} \operatorname{IgA}$ concentration in males on age for 1486 observations. Number of original observations 1523 . Mean age $38.7 \mathrm{yr}$. $\log _{\mathrm{e}}$ concentration mean $=1.63$, S.D. $=1.75$. 


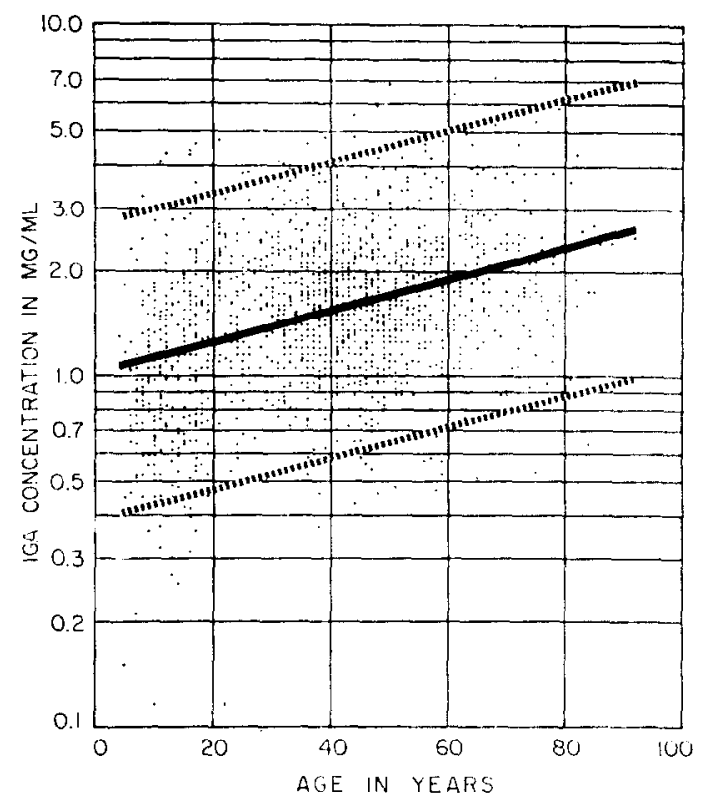

FIG. 4. Regression of $\log _{e} \operatorname{IgA}$ concentration in females on age for 1654 observations. Number of original observations 1687 . Mean age $38.7 \mathrm{yr}$. $\log _{e}$ concentration mean $=1.52$, S.D. $=1.70$.

marked sex difference in the age specific mean concentrations for IgM with females consistently higher than males (Figs. 5-6). The six immunoglobulin sex groups were in fact characterized as different populations.

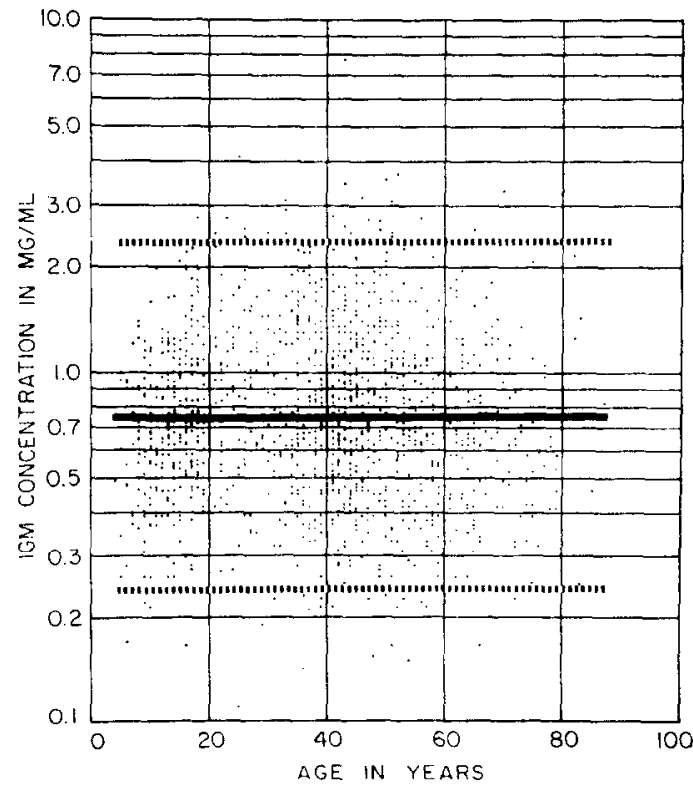

FIG. 5. Regression of $\log _{e}$ IgM concentration in males on age for 1488 observations. Number of original observations 1525 . Mean age $38.6 \mathrm{yr}$. $\log _{\mathrm{e}}$ concentration mean $=0.75$, S.D. $=1.79$. 


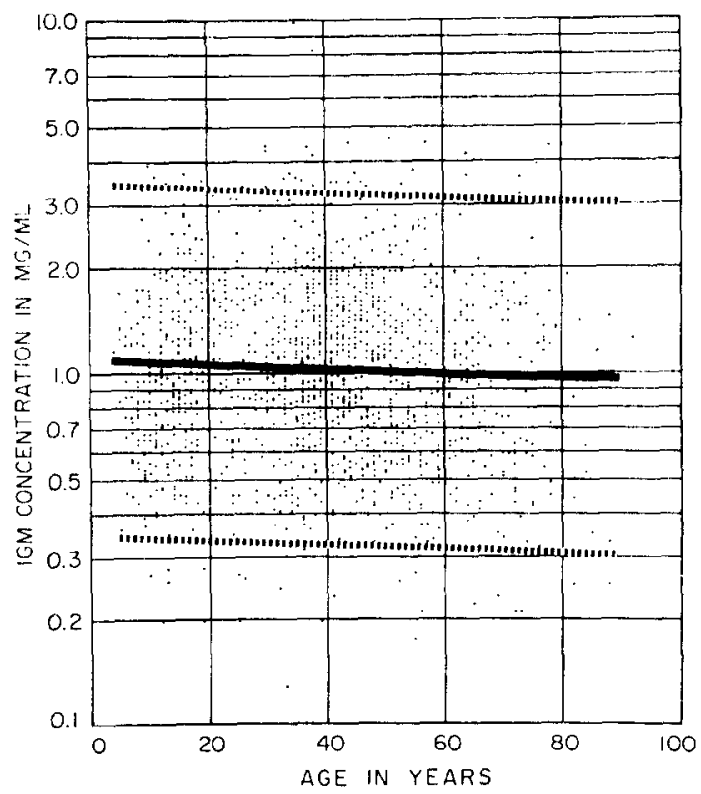

FIG. 6. Regression of $\log _{e}$ IgM concentration in females on age for 1653 observations. Number of original observations 1686 . Mean age $38.7 \mathrm{yr}$. $\log _{\mathrm{e}}$ concentration mean $=1.03$, S.D. $=1.80$.

\section{Age differences}

Ages are distributed as illustrated by the actual data points in Figs. 1-6. Linear regressions of log concentration against age are depicted together with bounds of the 95 per cent confidence limits. Regression on age revealed an age effect for IgA and IgG but none for IgM. Furthermore, a significant sex effect was noted on the slopes for each sex regression for $\mathrm{IgG}$ and $\mathrm{IgA}$. For IgM, slopes for each sex regression were indistinguishable from zero, as were the pooled estimates of the slopes.

Age specific concentrations for IgG increased slowly throughout the age range. The slopes of the regressions for IgA were steeper than for IgG. There was no significant change in the concentration of $\operatorname{IgM}$ with increasing age for either sex. There was no increase with age in the variability of the range of the data for any immunoglobulin class. Tests for homogeneity of variance for both sequential equal-age groups and sequential equal-size groups confirm that the data are homoscedastic at the 5 per cent level.

All regressions were found to be linear since additional power terms did not significantly reduce the residual variances. The relevant parameters of the computations are included in Table 1 . The residual standard deviations about the regression lines are shown in the third column of the table. By the variance ratio test, sex had no effect on residual variance, and pooled estimates of variance were therefore made: for $\operatorname{IgA}, s=0.0537$; for $\operatorname{IgG}, s=0.2936$; and for $\operatorname{IgM}, s=0.5832$. The pooled estimates were used in subsequent tests of significance and in computing ranges.

\section{Range of normal immunoglobulin values}

Using the regression equations, ranges of normal concentration values for IgG and IgA were computed. Table 2 displays these mean immunoglobulin concentrations in 
$\mathrm{mg} / \mathrm{ml}$. The lower and upper limits of a range which excluded 5 per cent of the values at each extreme, the 90 per cent confidence interval, are given for each of the age groups. For IgM the mean was $0.77 \mathrm{mg} / \mathrm{ml}$ for males and $1.06 \mathrm{mg} / \mathrm{ml}$ for females; the 90 per cent confidence interval was $0.30-2.01 \mathrm{mg} / \mathrm{ml}$ for males and $0.41-2.77 \mathrm{mg} / \mathrm{ml}$ for females. Sera with large deviations from the mean were reexamined by immunoelectrophoresis. No qualitative abnormalities were identified in immunoglobulins.

TABle 1. Regression PARAMETERS FOR THE MODEL $\log _{\mathbf{e}}($ CONCENTRATION $)=$ MEAN $(y)+$ $B$ (AGE)

\begin{tabular}{|c|c|c|c|c|}
\hline $\begin{array}{l}\mathrm{Jg} \\
\text { Class }\end{array}$ & Sex & $\begin{array}{c}\text { Residual } \\
\text { S.D. }\end{array}$ & Mean $(y)$ & Slope \\
\hline IgG & $\begin{array}{l}\mathrm{M} \\
\mathrm{F}\end{array}$ & $\begin{array}{l}0.291 \\
0.296\end{array}$ & $\begin{array}{l}2.4132 \pm 0.0149 \\
2.4450 \pm 0.0141\end{array}$ & $\begin{array}{l}2.6337 \pm 0.8155 \times 10^{-3} \\
1.3313 \pm 0.7766 \times 10^{-3}\end{array}$ \\
\hline IgA & $\begin{array}{l}M \\
F\end{array}$ & $\begin{array}{l}0.511 \\
0.497\end{array}$ & $\begin{array}{l}0.4874 \pm 0.0256 \\
0.4181 \pm 0.0243\end{array}$ & $\begin{array}{l}1.2798 \pm 0.1401 \times 10^{-2} \\
1.0317 \pm 0.1332 \times 10^{-2}\end{array}$ \\
\hline IgM & $\begin{array}{l}\mathrm{M} \\
\mathrm{F}\end{array}$ & $\begin{array}{l}0.580 \\
0.586\end{array}$ & $\begin{array}{r}-0.2890 \pm 0.0296 \\
0.0315 \pm 0.0281\end{array}$ & $\begin{array}{r}0.1556 \pm 1.6198 \times 10^{-3} \\
-1.5179 \pm 1.5430 \times 10^{-3}\end{array}$ \\
\hline
\end{tabular}

TABle 2. Serum immunoglobulin CONCENTRATIONS: SEX-AGE SPECIFIC MEANS AND RANGes

\begin{tabular}{|c|c|c|c|c|c|c|c|c|}
\hline \multirow[t]{4}{*}{$\begin{array}{r}\text { Age } \\
(\mathrm{yr})\end{array}$} & \multicolumn{8}{|c|}{ Immunoglobulin concentrations in $\mathrm{mg} / \mathrm{ml}$} \\
\hline & \multicolumn{4}{|c|}{ IgG } & \multicolumn{4}{|c|}{$\operatorname{Ig} \mathbf{A}$} \\
\hline & & Male & & emale & & Male & & emale \\
\hline & Mean & Range* & Mean & Range* & Mean & Range* & Mean & Range* \\
\hline $5-9$ & 10.28 & $6.34-16.65$ & 11.05 & $6.82-17.92$ & 1.09 & $0.47-2.49$ & 1.10 & $0.48-2.51$ \\
\hline $10-14$ & 10.41 & $6.42-16.88$ & 11.13 & $6.87-18.04$ & 1.16 & $0.51-2.65$ & 1.15 & $0.50-2.64$ \\
\hline $15-19$ & 10.55 & $6.51-17.10$ & 11.20 & $6.91-18.16$ & 1.23 & $0.54-2.83$ & 1.21 & $0.53-2.78$ \\
\hline $20-24$ & 10.69 & $6.60-17.33$ & 11.28 & $6.96-18.28$ & 1.32 & $0.57-3.01$ & 1.28 & $0.56-2.93$ \\
\hline $25-29$ & 10.83 & $6.68-17.56$ & 11.35 & $7.00-18.40$ & 1.40 & $0.61-3.21$ & 1.35 & $0.59-3.08$ \\
\hline $30-34$ & 10.98 & $6.77-17.79$ & 11.43 & $7.05-18.52$ & 1.50 & $0.65-3.42$ & 1.42 & $0.62-3.25$ \\
\hline $35-39$ & 11.12 & $6.86-18.03$ & 11.50 & $7.10-18.65$ & 1.59 & $0.70-3.65$ & 1.49 & $0.65-3.42$ \\
\hline $40-44$ & 11.27 & $6.95-18.27$ & 11.58 & $7.14-18.77$ & 1.70 & $0.74-3.89$ & 1.57 & $0.69-3.60$ \\
\hline $45-49$ & 11.42 & $7.04-18.50$ & 11.66 & $7.19-18.90$ & 1.81 & $0.79-4.15$ & 1.65 & $0.72-3.79$ \\
\hline $50-54$ & 11.57 & $7.14-18.75$ & 11.74 & $7.24-19.02$ & 1.93 & $0.84-4.42$ & 1.74 & $0.76-3.99$ \\
\hline $55-59$ & 11.72 & $7.23-19.00$ & 11.81 & $7.29-19.15$ & 2.06 & $0.90-4.72$ & 1.83 & $0.80-4.20$ \\
\hline $60-64$ & 11.88 & $7.33-19.25$ & 11.89 & $7.34-19.28$ & 2.20 & $0.96-5.03$ & 1.93 & $0.84-4.42$ \\
\hline $65-69$ & 12.04 & $7.43-19.51$ & 11.97 & $7.39-19.41$ & 2.34 & $1.02-5.36$ & 2.03 & $0.89-4.66$ \\
\hline $70-74$ & 12.20 & $7.52-19.77$ & 12.05 & $7.44-19.54$ & 2.49 & $1.09-5.71$ & 2.14 & $0.94-4.91$ \\
\hline $75+$ & 12.36 & $7.62-20.03$ & 12.13 & $7.49-19.67$ & 2.66 & $1.16-6.09$ & 2.26 & $0.98-5.16$ \\
\hline
\end{tabular}

* Range is expressed in $\mathrm{mg} / \mathrm{ml}$ and defines the interval within which 90 per cent of the data are expected to fall. For IgM the mean is $0.77 \mathrm{mg} / \mathrm{ml}$ with a range of $0.30-2.01 \mathrm{mg} / \mathrm{ml}$ for males, and $1.06 \mathrm{mg} / \mathrm{ml}$ with a range of $0.41-2.77 \mathrm{mg} / \mathrm{ml}$ for females. 


\section{DISCUSSION}

Recent studies have concluded that immunoglobulin concentrations are lognormally distributed $[1,4,19]$. One consequence of this fact is that ranges of average concentrations cannot be expressed as symmetric confidence intervals about the mean in $\mathrm{mg} / \mathrm{ml}$ concentration units. Therefore the $\mathbf{9 0}$ per cent confidence limits in Table 2 are not symmetrical. These data as presented are clinically useful expressions of norms for the measured immunoglobulin classes for white individuals residing in the United States in the temperate zone, although seasonal variation was not a major factor in the present study. Racial admixture and large deviations in socioeconomic levels were not important aspects of this population group. The method of analysis of immunoglobulin concentration based upon radial diffusion assay is comparable to that in general use in clinical laboratories. In order to increase the usefulness of our data to other investigators, these values can be related to the International Reference Preparation by referral to the assays of 67/95 [13]. However, differences in antigenic specificity of antisera employed in various laboratories cannot be controlled by that procedure [20], so we have not expressed concentrations as percentages of the standard.

The unique data presented in this report were derived from analysis of a large number of consecutive sera in a study of a total community, thereby avoiding many of the biases of preselection of individuals. Two constraints were inherent in this population: the lack of authorization to obtain blood on children younger than $4 \mathrm{yr}$ of age, and the under-representation of the 20-30 yr age group, particularly in males, owing to the outward mobility of young adults in such a community related to education, military service and employment.

The immunoglobulin values provided by this study have proved useful to us in analyses of diseased populations by providing norms for standardization of immunoglobulin concentrations [21]. This process of normalization permits expression of sex and age corrected immunoglobulin values in relation to the spectrum of concentrations observed in this population study and allows valid intragroup comparisons by the subsequent use of statistical procedures which employ parametric concepts.

Previous studies have described variations in serum immunoglobulin concentrations based upon race [2,3], age $[1,4,19]$, and sex [22]. There has not been agreement, however, on the correct expression of the varying trends that were observed in these studies, especially for age effect. Some of the study groups have been small in comparison to the present one and most were biased by not representing community samples.

Conclusions supporting aspects of the present study were obtained by Kalff who summarized all previous investigations and in addition reported data on 252 sera divided into nine age groups of 15 males and 15 females each [4]. No sex differences were found for IgG and IgA, but concentrations did increase with age. Concentrations of IgM were higher in females, and the mean concentration of IgM did not change with age.

Somewhat different conclusions were drawn by Buckley and Dorsey $[1,19]$. Their studies included 811 individuals of the white and black races. They described a fall in mean concentrations of IgG and IgM after the age of $35 \mathrm{yr}$; in contrast, serum IgA concentrations were well maintained. These authors confirmed the observation that mean IgM levels were higher in females. Differences in concentrations of IgG and IgA based upon sex were found to be small. In the present study, IgM concentrations 
were markedly higher in females in agreement with previous reports $(1,4,19,22)$. Serum levels of IgG were slightly increased in females, whereas IgA levels were somewhat higher in males. Although these sex differences for IgG and IgA were statistically significant, they do not have any biologic meaning that is immediately apparent.

In the present study, mean IgG and IgA concentrations increased progressively with age of the population and serum levels of IgM were maintained at a stable value throughout the adult years. Buckley and Dorsey employed polynomial analysis in reaching their conclusion that aging was associated with a decrease in IgG and IgM concentrations $[1,19]$. In the present study we did not find that polynomial analysis improved the regression of the data using the unbiased estimate of residual variance as the criterion.

All of these studies including the present one have used cross-sectional analysis to identify trends which might be applicable to a single individual throughout his lifetime. Therefore, our results must be interpreted cautiously as individual trends might differ considerably from cohort analysis. There is evidence, however, that whole gamma globulin concentrations increase progressively in individuals studied longitudinally between the ages of 4 and $20 \mathrm{yr}$ [23] in agreement with the conclusions of the present study.

\section{SUMMARY}

Concentrations of serum immunoglobulins provide clinically useful parameters of immunologic or inflammatory diseases. Valid interpretations of these data require recognition of biologic variations which exist throughout the life-span of the individual. The most important of these variables are sex, age and race. The present study reports the sex-age specific changes in serum immunoglobulin concentrations in 3213 unselected individuals from 5 to $94 \mathrm{yr}$ of age from a community study. Evaluation of biologic differences was accomplished by multiple linear regression on $\log _{e}$ transformed data.

IgG and IgA concentrations increased with age with slight but significant differences between the sexes. Females had higher serum levels of IgG and lower levels of IgA than males. IgM levels did not change with age and were significantly higher in females than in males. None of the immunoglobulin concentrations decreased with age, nor was there a change in variability. These observations document significant biologic variations which occur in immunoglobulin concentrations and are the first data available based on an unbiased community sample.

Acknowledgements-The authors thank Louise Brown, B.S., Angela Martin, R.N., and Ann Burt, M.T., for technical assistance in this study, Viktors Berstis and Stephen Burton for computer programing, and Dr. Wilma Donahue, former director of the Institute of Gerontology for kind encouragement and advice.

\section{REFERENCES}

1. Buckley CE III, Dorsey FC: The effect of aging on human serum immunoglobulin concentrations. J Immunol 105: 964-972, 1970

2. Milner LV, Calitz F: Serum immunoglobulin levels in white Asiatic and Bantu blood donors. S Afr Med J 45: 683-685, 1971

3. Lichtman MA, Vaughan JH, Hames CG: The distribution of serum immunoglobulins, anti$\gamma-\mathrm{G}$ globulins ('Rheumatoid Factors') and antinuclear antibodies in white and negro subjects in Evans County, Georgia. Arthritis Rheum 10: 204-215, 1967 
4. Kalff MW: A population study on serum immunoglobulin levels. Clin Chim Acta 28: 277-289, 1970

5. Peterson EA, Sober HA: Column chromatography of proteins: substituted celluloses, Methods in Enzymology, Vol. 5. Colowick SP, Kaplan NO (eds), New York: Academic Press, 1962, pp. 3-27

6. Kunkel HG, Slater RJ: Zone electrophoresis in a starch supporting medium. Proc Soc Exp Biol Med 80: 42-44, 1952

7. Flodin $\mathbf{P}$, Killander J: Fractionation of human-serum proteins by gel filtration. Biochim Biophys Acta $63: 403-410,1962$

8. Miller F, Metzger $\mathbf{H}$ : Characterization of a human macroglobulin. I. The molecular weight of its subunit. J Biol Chem 240: 3325-3333, 1965

9. Ouchterlony O: Diffusion-in-gel methods for immunological analysis. Progr Allergy 5: 1-78, 1958

10. Scheidegger JJ: Une micro-méthode de l'immuno-électrophorèse. Int Arch Allergy Appl Immunol 7: $103-110,1956$

11. Steyermark A: Quantitative Organic Microanalysis. 2nd Ed. New York: Academic Press, 1961, pp. 205-209

12. Svedberg T, Pedersen KO: The Ultracentrifuge. New York: Oxford University Press, $\mathbf{1 9 4 0}$

13. Rowe DS, Anderson SG, Grab B: A research standard for human serum immunoglobulins IgG, IgA and IgM. Bull WHO 42: 535-552, 1970

14. Fahey JL, McKelvey EM: Quantitative determination of serum immunoglobulins in antibodyagar plates. J Immunol 94: 84-90, 1965

15. Laurell C-B: Quantitative estimation of proteins by electrophoresis in agarose gel containing antibodies. Anal Biochem 15: 45-52, 1966

16. Dixon WJ, Massey FJ Jr: Introduction to Statistical Analysis. 3rd Ed. New York: McGraw-Hill, 1969, pp. 328-330

17. Hald A: Statistical Theory With Engineering Applications. New York: Wiley, 1952, pp. 522-584

18. Bartels RCF (ed): The Michigan Terminal System. 3rd Ed. Ann Arbor. The University of Michigan Computing Center, 1971

19. Buckley CE III, Dorsey FC: Serum immunoglobulin levels throughout the life-span of healthy man. Ann Int Med 75: 673-682, 1971

20. Rowe DS, Grab B, Anderson SG: An international reference preparation for human serum immunoglobulins G, A and M: content of immunoglobulins by weight. Bull WHO 46: 67-79, 1972

21. Cassidy JT, Petty RE, Sullivan DB: Abnormalities in the distribution of serum immunoglobulin concentrations in juvenile rheumatoid arthritis. J Clin Invest 52: 1931-1936, 1973

22. Butterworth $\mathbf{M}$, McClellan $\mathbf{B}$, Allansmith $\mathbf{M}$ : Influence of sex on immunoglobulin levels. Nature, Lond 214: 1224-1225, 1967

23. Trevorrow VE: Intra-individual gamma globulin changes with age from 4 to 20 years. Human Biol 39: 1-4, 1967 